\title{
Anomalous origin of culprit coronary arteries in acute coronary syndromes
}

\author{
Paweł Tyczyński ${ }^{1}$, Krzysztof Kukuła ${ }^{1}$, Arkadiusz Pietrasik ${ }^{2}$, Tomasz Bochenek ${ }^{3}$, \\ Artur Dębski ${ }^{1}$, Anna Oleksiak ${ }^{4}$, Miłosz Marona ${ }^{4}$, Michał Lelek ${ }^{3}$, \\ Janina Stępińska ${ }^{4}$, Adam Witkowski ${ }^{1}$
}

${ }^{1}$ Department of Interventional Cardiology and Angiology, Institute of Cardiology, Warsaw, Poland

${ }^{2}$ First Department of Cardiology, Medical University of Warsaw, Warsaw, Poland

${ }^{3}$ First Department of Cardiology, Medical University of Silesia, Katowice, Poland

${ }^{4}$ Department of Intensive Cardiac Therapy, Institute of Cardiology, Warsaw, Poland

\begin{abstract}
Background: The aim of the study was to describe a series of acute coronary syndrome (ACS) patients in whom anomalous origin of culprit coronary artery (AOCCA) was diagnosed. Percutaneous coronary interventions (PCI) in AOCCA are performed very infrequently.

Methods: Electronic databases from three high-volume tertiary cardiac centers were retrospectively searched for the presence of AOCCA in ACS.

Results: Different types of AOCCA in ACS were identified in 20 patients. The most frequent AOCCA was left circumflex coronary artery $(L C x)$ originating from right coronary artery $(R C A)$ or directly from the right coronary sinus (RCS), $n=13$, followed by high/atypical $R C A, n=3$, left coronary artery $(L C A)$ originating from $R C S(n=3)$ with either RCA-AOCCA $(n=1)$ or left anterior descending coronary artery $(L A D)-A O C C A(n=1)$ or RCA originating from left sinus of Valsalva, $(n=1), L A D$ originating from RCA $(n=1)$. In 1 ST-segment elevation myocardial infarction (STEMI)-patient RCA-AOCCA cannulation was unsuccessful, in 1 non-STEMI-patient AOCCA was missed, 1 ACS-patient was treated surgically and 1 ACS-patient was treated conservatively (both patients with nonSTEMI). In the remaining patients PCI was successfully performed.

Conclusions: The most frequently encountered AOCCA is LCX branching-off from RCA. AOCCA may either be difficult to cannulate and PCI aborted even in STEMI, or missed, especially when the intermediate branch from LCA is mimicking proper LCX. (Cardiol J 2018; 25, 6: 683-690)

Key words: anomalous origin culprit coronary artery, percutaneous coronary intervention, acute coronary syndrome
\end{abstract}

\section{Introduction}

Anomalous origin of coronary arteries is an infrequent finding in invasive angiography or computed tomography studies. Based on serial computed tomography angiography studies the prevalence of all cases of anomaly is around 1.5\% [1]. Different anatomical scenarios of anomalous origins of coronaries have been described. Specifi- cally, the incidence of anomalous origin of the left coronary artery from the right sinus of Valsalva or from the right coronary artery (RCA), thus constituting single coronary artery, is around $0.1 \%$. Left circumflex coronary artery ( $\mathrm{LCx}$ ) taking-off from RCA or the right sinus of Valsalva is seen in around $0.2 \%$ of cases. High take-off of the RCA is observed in about $0.6 \%$ of cases [1,2]. Several definitions and classifications of these anomalies

Address for correspondence: Paweł Tyczyński, MD, PhD, Department of Interventional Cardiology and Angiology, Institute of Cardiology, ul. Alpejska 42, 04-628 Warszawa, Poland, e-mail: medykpol@wp.pl 
have been proposed [3]. Anomalous left coronary artery originating from the right sinus of Valsalva may have four pathways: interatrial, trans-septal (or subpulmonic), anterior (or prepulmonic) and posterior to the aortic root (or retroaortic) [4]. A "high take-off" is variably referred to as the coronary origin above the sinotubular junction. However, such a definition might be inappropriately broad, and include near-normal anatomical variants.

A major consideration in patients with anomalous coronaries is the potential for sudden cardiac death and not acute coronary syndrome (ACS) due to culprit lesions located in these arteries [5]. Interestingly, in an impressive study of more than 126,000 coronary angiographies, anomalous LCx originating from $\mathrm{RCA} /$ the right sinus of Valsalva was identified in 467 cases. Still, none of these patients had angina pectoris or ACS [6]. Thus, due to the rarity of such anomalies and concomitant atherosclerosis, percutaneous coronary interventions (PCI) in anomalous origin of culprit coronary arteries (AOCCA) are performed infrequently. Such intervention may carry additional difficulties and increased risk of ostial dissection.

Adequate selective transcatheter visualization and treatment are often more difficult than with conventional anatomy and can be facilitated by preliminary information offered by non-invasive imaging. However, in the setting of ACS, it may not be feasible. There are few reports on PCI in AOCCA of ACS-patients $[3,4,7]$ and apart from one series of 5 culprit AOCCA's in ACS-patients [8], there is no systematic study of patients who underwent PCI of AOCCA, especially in emergency cases.

Described herein is a series of ACS-patients in whom AOCCA was diagnosed and who were successfully treated with PCI in most of the cases.

\section{Methods}

Electronic databases from three high-volume tertiary cardiac centers (Institute of Cardiology, Warsaw, Medical University of Warsaw and Medical University of Silesia) of all coronary angiography reports of ACS-patients were retrospectively searched for the presence of AOCCA. Reports of coronary angiography done in the settings of ACS were identified in hospital databases and the following keywords were used to identify AOCCA among them: "anomalous coronary artery", "anomalous or atypical take-off", "left circumflex coronary artery (LCx) or left coronary artery originating from right", "right coronary artery (RCA) originating from left". As the electronic databases were introduced at dif- ferent times, they cover somewhat different periods and range from 2008 to 2016. Patient charts and angiographic recordings were reviewed. Demographics and clinical presentations were reviewed. The requirement for informed consent was waived because of the retrospective nature of the study.

\section{Results}

A total of 20 patients with different types of AOCCA in the setting of ACS were identified (Table 1). The most frequently diagnosed coronary anomaly was LCx originating from RCA (Fig. 1), or directly from the right sinus of Valsalva just beside RCA $(n=13)$ with either LCx-AOCCA $(n=9)$ or RCA-AOCCA $(n=4)$, followed by high/atypical RCA origin $(\mathrm{n}=3$ ) (Fig. 2), left coronary artery originating from the right sinus of Valsalva $(n=3)$ with either RCA-AOCCA $(n=1)$ or left anterior descending coronary artery (LAD)-AOCCA $(n=1)$ or LAD originating from RCA $(n=1)$, (Fig. 3$)$, RCA originating from the left coronary artery $(n=1)$ (Fig. 4). In 1 ST-segment elevation myocardial infarction (STEMI)-patient RCA-AOCCA cannulation was unsuccessful, in 1 non-STEMI-patient LCX-AOCCA was missed, 1 non-STEMI-patient was treated surgically, and 1 non-STEMI-patient was treated conservatively. In the remaining cases PCI was successfully performed.

Demographics, clinical presentation and procedural details are presented in Table 2 . Ten patients presented with STEMI, 8 patients with non-STEMI and 2 had unstable angina.

AOCCA frequency was calculated for two of three participating centers. At the Institute of Cardiology in Warsaw 4531 PCI's were performed for ACS patients during the period in question (from 2008 to 2016). In 9 (8 males) of these patients AOCCA was identified, giving the prevalence of $0.19 \%$. At the Medical University of Warsaw 7561 PCI for ACS patients were done (from 2006 to 2016). Thus, AOCCA prevalence was $0.1 \%$.

\section{Discussion}

As documented by the presented evidence, AOCCA is an infrequent finding, which however, may hinder the appropriate treatment of ACS. Several problems may be encountered during the angiography and angioplasty of AOCCA, including precise diagnosis, selection of an appropriate guiding catheter, insufficient backup force, and difficulties in balloon or stent delivery. Thus, the careful assessment of the AOCCA configuration, proximal 
Table 1. Demographics, previous medical history and clinical presentation.

\begin{tabular}{|c|c|c|c|c|c|c|c|c|c|c|}
\hline \multirow{2}{*}{$\begin{array}{l}\text { Patient } \\
\text { no. }\end{array}$} & \multicolumn{2}{|c|}{ Demographics } & \multicolumn{6}{|c|}{ Previous medical history } & \multirow{2}{*}{$\begin{array}{c}\text { Clinical } \\
\text { presentation }\end{array}$} & \multirow{2}{*}{$\begin{array}{c}\text { LVEF } \\
\text { [\%] }\end{array}$} \\
\hline & $\begin{array}{c}\text { Age } \\
\text { [years] }\end{array}$ & Sex & DM & Stroke & HT & Nicotine & ACS & $\begin{array}{l}\mathrm{PCl} \text { or } \\
\mathrm{CABG}\end{array}$ & & \\
\hline 1 & 47 & M & - & - & + & - & + & + & NSTEMI & 60 \\
\hline 2 & 45 & $\mathrm{M}$ & - & - & - & - & - & - & STEMI & 65 \\
\hline 3 & 56 & $\mathrm{M}$ & - & - & - & + & - & - & STEMI & 45 \\
\hline 4 & 89 & $\mathrm{M}$ & - & - & - & + & - & - & STEMI & 40 \\
\hline 5 & 67 & $\mathrm{~F}$ & - & - & + & - & - & - & STEMI* & 62 \\
\hline 6 & 56 & $\mathrm{M}$ & - & - & + & - & - & - & NSTEMI** & 45 \\
\hline 7 & 60 & $\mathrm{M}$ & + & - & + & - & - & - & NSTEMI & 50 \\
\hline 8 & 75 & $\mathrm{M}$ & + & - & + & - & - & + & UA & 50 \\
\hline 9 & 37 & $\mathrm{M}$ & - & - & - & - & - & - & NSTEMI & 60 \\
\hline 10 & 82 & $F$ & - & - & + & - & - & - & UA & 50 \\
\hline 11 & 33 & $\mathrm{M}$ & - & - & - & - & - & - & STEMI & 60 \\
\hline 12 & 48 & $\mathrm{M}$ & - & - & - & + & - & - & STEMI & 60 \\
\hline 13 & 56 & $\mathrm{M}$ & - & - & + & + & - & - & STEMI & 58 \\
\hline 14 & 85 & M & - & - & + & - & - & - & NSTEMI & 55 \\
\hline 15 & 44 & $M$ & - & - & - & + & + & - & STEMI & 55 \\
\hline 16 & 51 & $\mathrm{M}$ & + & - & + & + & - & - & NSTEMI & 50 \\
\hline 17 & 82 & $F$ & - & - & + & - & - & - & NSTEMI & 60 \\
\hline 18 & 50 & $M$ & - & - & + & - & - & - & STEMI & 55 \\
\hline 19 & 68 & $M$ & + & - & + & - & - & - & NSTEMI & 60 \\
\hline 20 & 67 & $\mathrm{M}$ & - & + & + & + & - & - & STEMI & 30 \\
\hline
\end{tabular}

*Prinzmetal angina; **Thromboembolism due to infective endocarditis; ACS - acute coronary syndrome; CABG — coronary artery by-pass grafting; DM - diabetes mellitus; F - female; HT - hypertension; LVEF — left ventricular ejection fraction; M - male; NSTEMI - non-ST-segment elevation myocardial infarction; $\mathrm{PCl}$ - percutaneous coronary intervention; STEMI — ST-segment elevation myocardial infarction; UA - unstable angina

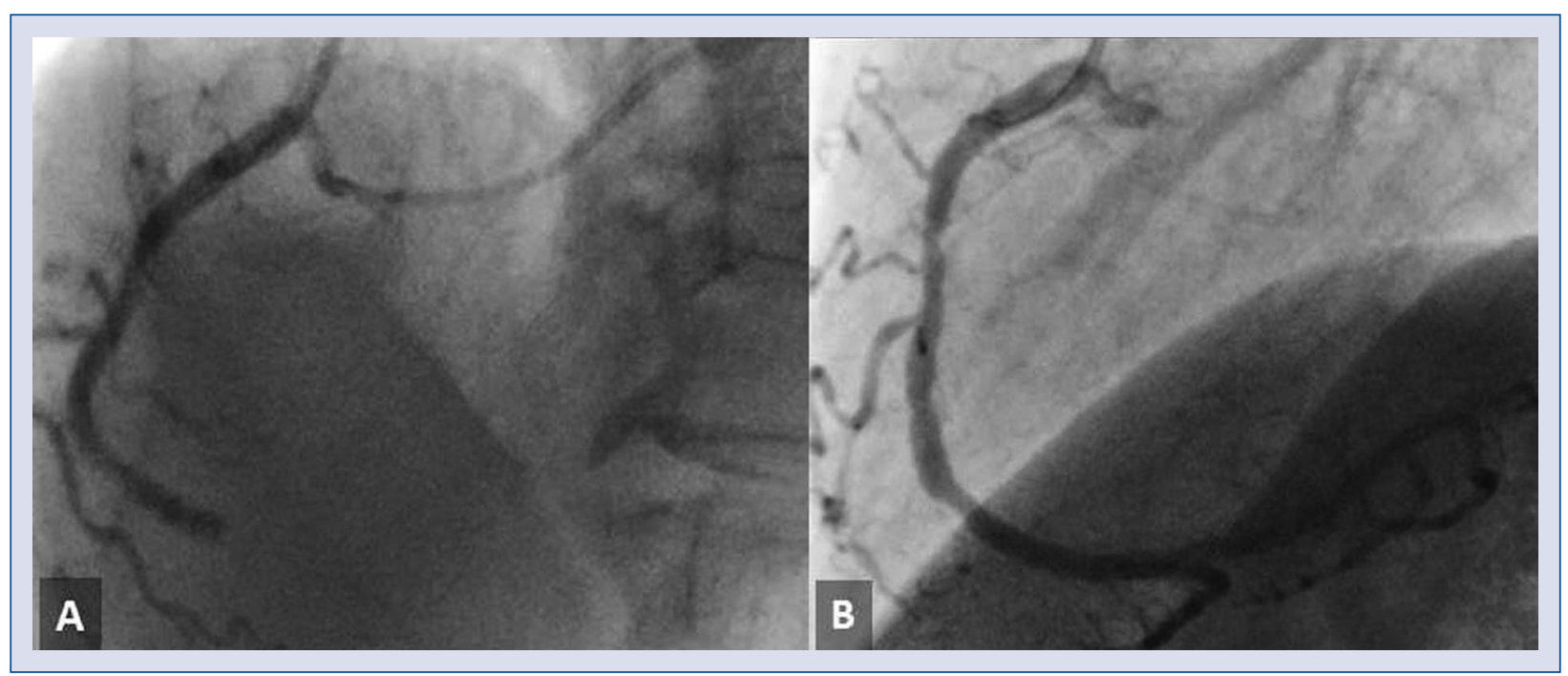

Figure 1. A. Culprit right coronary artery with its acute occlusion in the mid segment. Visible anomalous origin of the left circumflex coronary artery from the right coronary artery ostium; B. Final results after opening and stent implantation. 


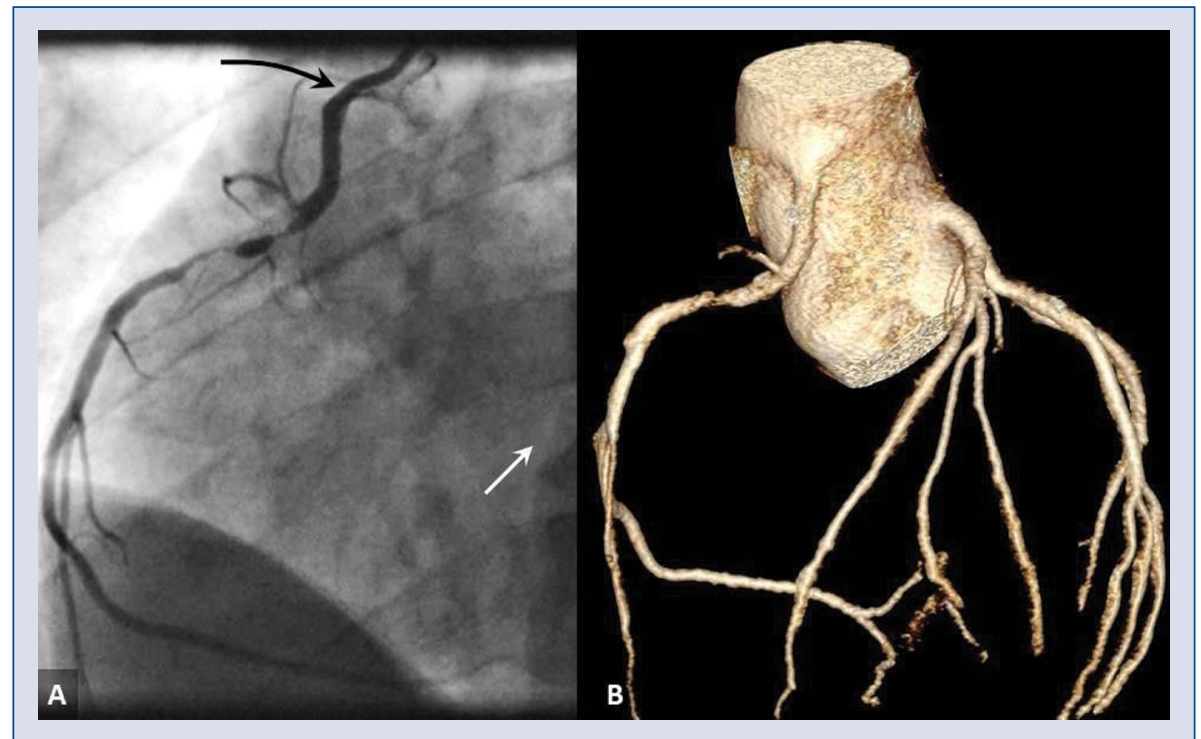

Figure 2. Culprit right coronary artery with very high take-off; A. Angiography. Black arrow indicates the coronary ostium and the white arrow indicates the right coronary cusp; B. Volume rendered computed tomography angiography.

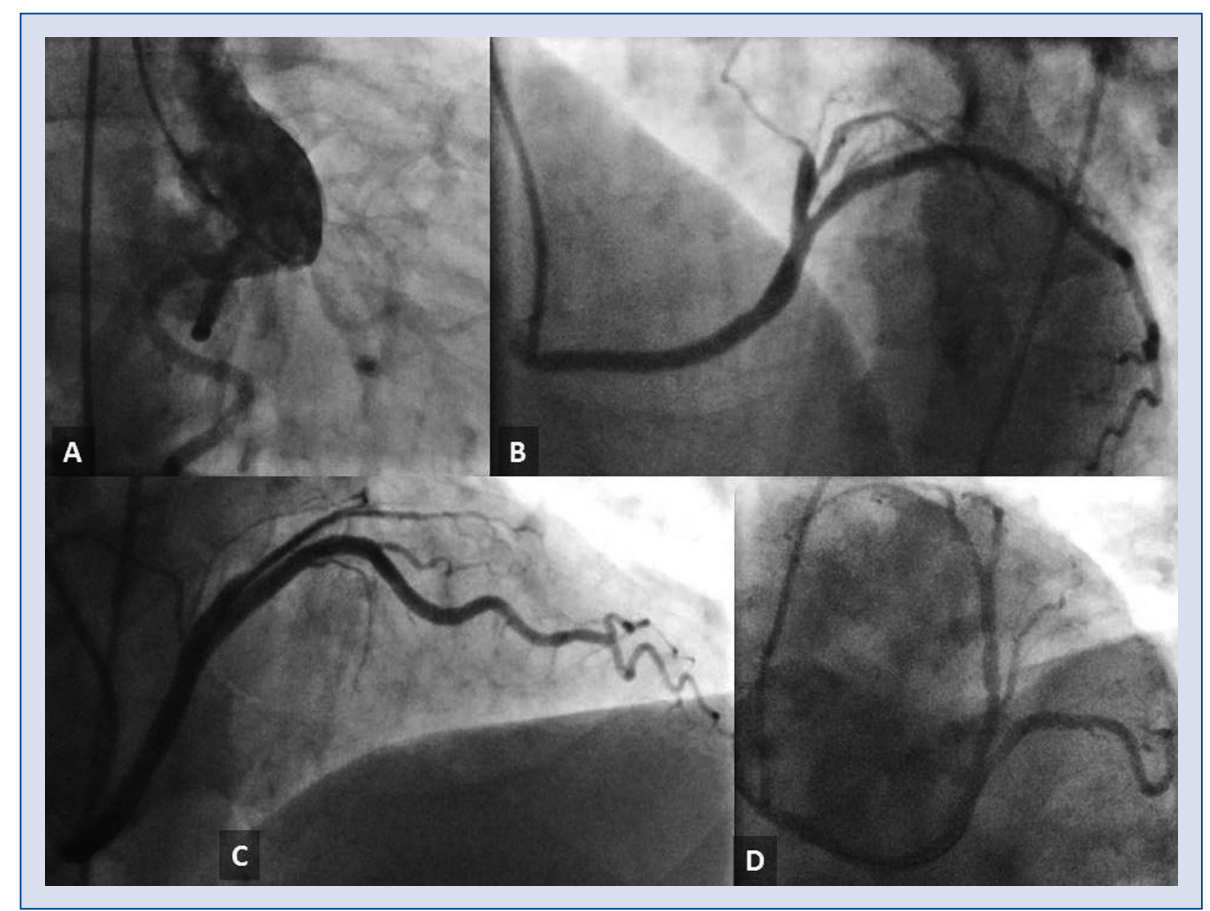

Figure 3. A. Right coronary artery; B. Left coronary artery taking-off from the right sinus of Valsalva with very long left main coronary artery and acutely occluded left anterior descending coronary artery in its proximal segment; C. Left circumflex coronary artery with small irregularities; D. Left anterior descending coronary artery after its opening.

angulation, vessel course and subsequent selection of an appropriate guide catheter and guidewire is critical to the final success of the procedure.

A relatively frequent scenario is the culprit $\mathrm{RCA}$ in the presence of anomalous LCx originating from the right sinus of Valsalva. Although it does not necessarily make PCI of RCA more difficult, the anomalous LCx may be difficult to visualize or be missed [4], while significant lesions in such an anomalous LCx seem relatively common. 


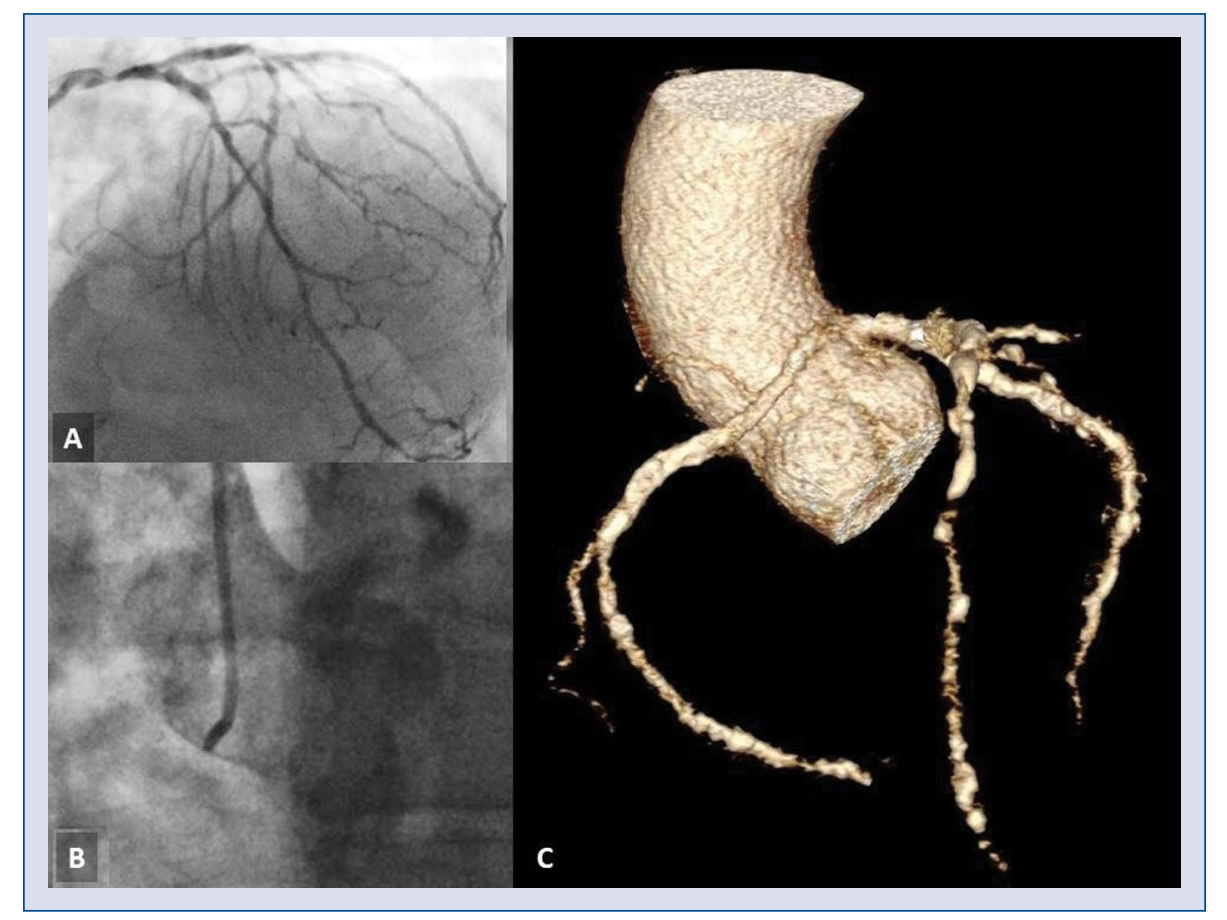

Figure 4. A. Angiography - tandem lesions in the left coronary artery; B. Angiography of the aortic root with no visible origin of the right coronary artery; C. Computed tomography image showing 3-vessel disease with the origin of the right coronary artery from the left sinus of Valsalva.

Below are some considerations regarding crucial aspects of AOCCA diagnosis and treatment.

- Femoral versus radial approach. Femoral access may offer better options in case of AOCCA, allowing for easy, multiple catheter exchanges, that may occasionally be needed in this setting. However, in the setting of ACS as discussed here, the operator is usually unaware of AOCCA presence, having to make the best use of the chosen access site. Also, it seems best to use the approach one is most comfortable with as there is usually a way to perform successful PCI of AOCCA regardless of access site.

- Right versus left radial approach. In a meta-analysis of 12 prospective randomized studies comparing aforementioned approaches there was a small but statistically significant difference in terms of contrast use and fluoroscopy time in favor of coronary procedures performed via left radial approach compared to the right radial approach, but without any difference in access site or other procedural complications [9].

Specifically, in STEMI patients, ambiguous results were observed, suggesting either no outcome difference between both radial approaches [10], or a left radial approach advantage [11]. There is no data comparing the ease of AOCCA cannulation, but one may speculate that at least in case of the most common one - $\mathrm{LCx}$ originating from $\mathrm{RCA}$, the usually greater elastic recoil of the guiding catheter in case of femoral or left radial access may increase the risk of $\mathrm{LCx}$ ostium dissection.

Additional tools. Anchoring balloons or anchor wire techniques may be helpful tools [12]. The latter maneuver was used to treat one of the present patients. Still, this technique was not proved for AOCCA. Extension catheters, such as Guideliner (Vascular Solutions, USA) or Guidezilla (Boston Scientific, USA) often allow for safe and stable intubation and facilitate stent placement.

Choice of the optimal guide catheter. Aggressive attempts to intubate AOCCA may lead to catheter-induced complications. Keeley et al. [13] reported that in more than $50 \%$ of 1000 consecutive PCI, placement of the guide catheter was associated with scraping debris from the aorta. Visible aortic debris occurred more frequently with the Judkins left and the Multipurpose guide catheters compared to any other type of guide catheter [13]. Aortic dissection is a devastating and potentially life-threatening condition. Data from the Registry of Aortic Iatrogenic Dissection (RAID) reported 
Table 2. Anatomical and procedural characteristics.

\begin{tabular}{|c|c|c|c|c|c|c|c|c|}
\hline \multirow{2}{*}{$\begin{array}{l}\text { Patient } \\
\text { no. }\end{array}$} & \multirow{2}{*}{$\begin{array}{l}\text { Coronary } \\
\text { anomaly }\end{array}$} & \multirow[t]{2}{*}{ ACCA } & \multicolumn{5}{|c|}{ Procedural characteristics } & \multirow{2}{*}{$\begin{array}{c}\text { Max TnT } \\
{[\mathrm{ng} / \mathrm{mL}]}\end{array}$} \\
\hline & & & $\begin{array}{l}\text { Vascular } \\
\text { approach }\end{array}$ & $\begin{array}{l}\text { Optimal } \\
\text { guide } \\
\text { catheter }\end{array}$ & $\begin{array}{l}\text { Stent/ } \\
\text { /POBA/ } \\
\text { /CABG }\end{array}$ & $\begin{array}{c}\text { Fluoroscopy } \\
\text { time [min] } \\
\text { (radiation } \\
\text { dose; mGy) }\end{array}$ & $\begin{array}{c}\text { Initial and } \\
\text { final TIMI } \\
\text { flow in } \\
\text { ACCA }\end{array}$ & \\
\hline 1 & LCx from RCA & LCx-ACCA & $\mathrm{RR}$ & - & DES & $23(1580)$ & $0 / 3$ & 1622 \\
\hline 2 & & & $\mathrm{RR}$ & $J R$ & 0 & $10.2(543)$ & $3 / 3$ & 2499 \\
\hline 3 & & & $\mathrm{RR}$ & AR1 & DES & 9.1 (2057) & $0 / 3$ & 35.5 \\
\hline 4 & & & $\mathrm{RR}$ & AL1 & DES & - & $3 / 3$ & - \\
\hline 5 & & & $\mathrm{Fe}$ & $J R$ & 0 & $4.3(232)$ & $3 / 3$ & 0 \\
\hline 6 & & & $\mathrm{RR}$ & JR 3.5 & $\begin{array}{l}\text { LCx (-) wire } \\
\text { did not } \\
\text { cross the } \\
\text { lesion }\end{array}$ & $22.1(606)$ & $0 / 0$ & 7.2 \\
\hline $7^{*}$ & & & $\mathrm{Fe}$ & $J R$ & DES & $18.6(721)$ & $3 / 3$ & 197 \\
\hline 8 & & & $\mathrm{Fe}$ & $J R$ & DES & $16.0(507)$ & $3 / 3$ & - \\
\hline 9 & & & $\mathrm{Fe}$ & EBU & DES & $14.2(760)$ & $3 / 3$ & 38 \\
\hline 10 & & RCA-ACCA & $\mathrm{Fe}$ & - & POBA & & $3 / 3$ & 128 \\
\hline 11 & & & $\mathrm{RR}$ & $J R$ & POBA & $5.0(292)$ & $2 / 2$ & 2284 \\
\hline 12 & & & $\mathrm{Fe}$ & $J R$ & DES & $4.4(639)$ & $0 / 3$ & 2027 \\
\hline 13 & & & $\mathrm{RR}$ & $J R$ & BMS & $5.5(510)$ & $3 / 3$ & 0.58 \\
\hline 14 & $\begin{array}{l}\text { High RCA } \\
\text { take-off }\end{array}$ & RCA-ACCA & $\mathrm{RR}$ & AR2 & DES & $11.6(820)$ & $3 / 3$ & 22 \\
\hline 15 & & & $\mathrm{RR}$ & $\mathrm{AL}$ & BVS & $5.5(415)$ & $3 / 3$ & - \\
\hline 16 & & & $\mathrm{RR}$ & & DES & 14 (1065) & $0 / 3$ & 1969 \\
\hline 17 & $\begin{array}{l}\text { LCA from } \\
\text { RSV }\end{array}$ & RCA-ACCA & $\mathrm{Fe}$ & AR1 & BMS & $10.3(301)$ & $2 / 3$ & 0,14 \\
\hline 18 & & LAD-ACCA & $\mathrm{Fe}$ & $\begin{array}{l}\text { Multi- } \\
\text { Purpose }\end{array}$ & BMS & $24.0(920)$ & $0 / 3$ & 138 \\
\hline 19 & $\begin{array}{c}\text { RCA from } \\
\text { LSV }\end{array}$ & $3 V-C A D$ & $\mathrm{RR}$ & AR1 & CABG & $33(2460)$ & $3 / 3$ & 140 \\
\hline 20 & $\begin{array}{l}\text { LAD from } \\
\text { RCA }\end{array}$ & LAD-ACCA & $\mathrm{RR}$ & AL1 & DES & $5.5(518)$ & $3 / 3$ & 88.0 \\
\hline
\end{tabular}

*Double culprit vessel: LCx from RCA and RCA; ACCA — anomalous culprit culprit artery; AL — Amplatz left; AR — Amplatz right; BMS - bare metal stent; BVS - bioabsorbable vascular scaffold; CABG - coronary artery by-pass grafting; DES - drug eluting stent; EBU — Extra Backup; Fe - femoral artery; JR - Judkins right; LAD - left anterior descending coronary artery; LCA - left coronary artery; LCx left circumflex coronary artery; LSV - left sinus of Valsalva; POBA — plain old balloon angioplasty; RCA — right coronary artery; RR — right radial artery; RSV — right sinus of Valsalva; TIMI — Thrombolysis In Myocardial Infarction; TnT — troponin T; 3V-CAD - three vessel coronary artery disease

the overall rate of aortic dissection at $0.06 \%$ [14]. Of note, in 5 out of 74 patients $(6.7 \%)$, there was AOCCA (among them 4 presented an aberrant LCx take-off). In the majority of cases (97\%) the problem coincided with an attempt to engage a vessel. The most frequent curve responsible in the femoral access cohort was a Judkins (42.9\%) and for the radial group was the Amplatz (38.9\%). However, these data only reflect more frequent Judkins use and should not be mistaken for catheter safety features.
Practical tips. In suspicion of coronary anomaly aortography may be helpful. Both, catheter size and curve are essential for successful intubation with adequate support. There is no universal guide to catheter selection in AOCCA and operators must rely on their experience and, to some extent, creativity. However, some recommendations may be taken into account:

- High RCA take-off. The artery take-off is usually both high and anterior. Judkins right and Amplatz right catheters are usually too 
short to achieve safe and selective intubation. Occasionally, large curves of these catheters may be successfully used along with extension catheters $[15,16]$. A better idea, though, is to use either Hockey Stick, Amplatz left, Left Venous Bypass Graft or XBRCA (Extra Backup RCA) catheters. From the present experience the easiest access is obtained with the Amplatz left catheter, but one must be careful, as coaxial alignment is often not possible especially with a right-AOCCA. A good practice is to quickly put a 0.014 wire into the AOCCA to improve the quality of the opacification and catheter stability.

Thus, deep intubation must be avoided or an extension catheter used.

- Anomalous LCx originating from the right sinus of Valsalva or from the origin of RCA. In these cases, standard intubation with a Judkins right catheter is often adequate. It may be preferable to use a larger curve of Judkins right (e.g. 5 or 6 ) and straighten the tip a little so it points somewhat downwards as this is the usual direction of LCx take-off in these cases. Other catheters, such as Amplatz right, Amplatz left, Multipurpose or Right Venous Bypass Graft may also be helpful in more difficult cases.

- Anomalous LCx originating independently from the left sinus of Valsalva. The LCx cannulation may be obtained using a larger size Judkins left catheter rotated in the posterior direction, Amplatz left or, in many cases, using Multipurpose catheter and rotating it until it catches the LCx take-off.

- Anomalous LAD originating from the right sinus of Valsalva. This anomaly is less often encountered than previous ones and the course of the LAD may vary. However, the artery often slants upwards, so shorter curve catheters may facilitate intubation.

\section{Limitations of the study}

The small number of patients precluded any statistical analysis. Secondly, the retrospective nature of this study did not allow an exact assessment of AOCCA frequency in all three participating centers. Although these numbers (see tables) may be underestimated, they are in line with aforementioned frequency of $\mathrm{LCx}$ taking-off from $\mathrm{RCA} /$ the right sinus of Valsalva $(0.2 \%)$ from computed tomography angiography observations $[1,2]$.

\section{Conclusions}

Although very infrequent, AOCCA may increase patient's risk in case as it may be misdiagnosed and difficult to cannulate. The procedure may have to be aborted even in STEMI. The culprit artery may be missed, especially when the intermediate branch from the left coronary artery is mimicking the proper $\mathrm{LCx}$.

\section{Impact on daily practice}

In case of AOCCA these practical tips are suggested and may help to cannulate such an artery, especially when it occurs in ACS.

\section{Conflict of interest: None declared}

\section{References}

1. Amado J, Carvalho M, Ferreira W, et al. Coronary arteries anomalous aortic origin on a computed tomography angiography population: prevalence, characteristics and clinical impact. Int J Cardiovasc Imaging. 2016; 32(6): 983-990, doi: 10.1007/s10554016-0849-5, indexed in Pubmed: 26852241.

2. Graidis C, Dimitriadis D, Karasavvidis V, et al. Prevalence and characteristics of coronary artery anomalies in an adult population undergoing multidetector-row computed tomography for the evaluation of coronary artery disease. BMC Cardiovasc Disord. 2015; 15: 112, doi: 10.1186/s12872-015-0098-x, indexed in Pubmed: 26431696.

3. Karur S, Patra S, Shankarappa RK, et al. Percutaneous coronary intervention in patients with anomalous origin of coronary artery presenting with acute coronary syndrome: A case series. J Cardiovasc Dis Res. 2013; 4(3): 204-208, doi: 10.1016/j. jcdr.2013.08.004, indexed in Pubmed: 24396264.

4. Lee $\mathrm{OhH}$, Yoon GS, Choi SH, et al. Anomalous origin of the left circumflex artery from the right sinus of valsalva: non-ST-segment elevation myocardial infarction. Intern Med. 2015; 54(9): 1053-1056, doi: 10.2169/internalmedicine.54.2956, indexed in Pubmed: 25948346.

5. Taylor AJ, Rogan KM, Virmani R. Sudden cardiac death associated with isolated congenital coronary artery anomalies. J Am Coll Cardiol. 1992; 20(3): 640-647, indexed in Pubmed: 1512344.

6. Yamanaka O, Hobbs RE. Coronary artery anomalies in 126,595 patients undergoing coronary arteriography. Cathet Cardiovasc Diagn. 1990; 21(1): 28-40, indexed in Pubmed: 2208265.

7. Vakili H, Khaheshi I, Memaryan M, et al. Anomalous Origin of a Stenosed Left Circumflex Coronary Artery in a Patient Presenting with Unstable Angina: A Case Report. Rom J Intern Med. 2016; 54(4): 247-249, doi: 10.1515/rjim-2016-0041, indexed in Pubmed: 27399610 .

8. Maagh P, Wickenbrock I, Prull MW, et al. Percutaneous coronary intervention in patients with acute myocardial infarction due to congenital coronary anomalies: technical skills and clinical outcome. Acute Card Care. 2011; 13(3): 148-154, doi: 10.3109/1748 2941.2011.553235, indexed in Pubmed:21410310.

9. Shah RM, Patel D, Abbate A, et al. Comparison of transradial coronary procedures via right radial versus left radial artery approach: A meta-analysis. Catheter Cardiovasc Interv. 2016; 88(7): 1027-1033, doi: 10.1002/ccd.26519, indexed in Pubmed: 27037544. 
10. Pristipino C. Radial versus femoral access in ACSs. Lancet. 2011; 378: 661.

11. Elmahdy MF, ElMaghawry M, Hassan M, et al. Comparison of safety and effectiveness between right versus left radial arterial access in primary percutaneous coronary intervention for acute ST segment elevation myocardial infarction. Heart Lung Circ. 2017; 26(1): 35-40, doi:10.1016/j.hlc.2016.04.021, indexed in Pubmed: 27374862.

12. Hamood H, Makhoul N, Grenadir E, et al. Anchor wire technique improves device deliverability during PCI of CTOs and other complex subsets. Acute Card Care. 2006; 8(3): 139-142, doi: 10.1080/17482940600885469, indexed in Pubmed: 17012127.

13. Keeley EC, Grines CL. Scraping of aortic debris by coronary guiding catheters: a prospective evaluation of 1,000 cases. J Am Coll Cardiol. 1998; 32(7): 1861-1865, indexed in Pubmed: 9857864.
14. Núñez-Gil IJ, Bautista D, Cerrato E, et al. Registry on Aortic Iatrogenic Dissection (RAID) Investigators. Incidence, Management, and Immediate- and Long-Term Outcomes After Iatrogenic Aortic Dissection During Diagnostic or Interventional Coronary Procedures. Circulation. 2015; 131(24): 2114-2119, doi: 10.1161/CIRCULATIONAHA.115.015334, indexed in Pubmed: 25888682.

15. Matsumoto M, Tamanaha Y, Tsurumaki Y, et al. GuideLiner Catheter Use for Percutaneous Intervention Involving Anomalous Origin of a Single Coronary Trunk Arising from the Ascending Aorta. Case Rep Cardiol. 2016; 2016: 8790347, doi: 10.1155/2016/8790347, indexed in Pubmed: 27529036.

16. Boukhris M, Azzarelli S, Tomasello SD, et al. The guideliner catheter: a useful tool in the armamentarium of the interventional cardiologist. J Tehran Heart Cent. 2015; 10(4): 208-214, indexed in Pubmed: 26985211. 